\title{
Impact of septal myectomy on diastolic function in patients with obstructive hypertrophic cardiomyopathy
}

\author{
Qiulan Yang ${ }^{1}$, Hao Cui ${ }^{2}$, Changsheng Zhu' ${ }^{1}$, Haibo $\mathrm{Hu}^{3}$, Jianhua $\mathrm{Lv}^{3}$, Yao Liu ${ }^{3}$, Yang Zhang ${ }^{4}$, \\ Hartzell V. Schaff ${ }^{2}$, Shuiyun Wang ${ }^{1}$
}

${ }^{1}$ Department of Cardiovascular Surgery, Fuwai Hospital, National Center for Cardiovascular Diseases, Chinese Academy of Medical Sciences and Peking Union Medical College, Beijing, China; ${ }^{2}$ Department of Cardiovascular Surgery, Mayo Clinic, Rochester, Minnesota, USA; ${ }^{3}$ Center of Structure Heart Disease, Fuwai Hospital, National Center for Cardiovascular Diseases, Chinese Academy of Medical Sciences and Peking Union Medical College, Beijing, China; ${ }^{4}$ Department of Cardiology, Fuwai Hospital, National Center for Cardiovascular Diseases, Chinese Academy of Medical Sciences and Peking Union Medical College, Beijing, China

Contributions: (I) Conception and design: S Wang; (II) Administrative support: H Cui, C Zhu, H Hu; (III) Provision of study materials or patients: None; (IV) Collection and assembly of data: Q Yang; (V) Data analysis and interpretation: Q Yang, H Cui; (VI) Manuscript writing: All authors; (VII) Final approval of manuscript: All authors.

Correspondence to: Shuiyun Wang. Department of Cardiovascular Surgery, Fuwai Hospital, National Center for Cardiovascular Diseases, Chinese Academy of Medical Sciences and Peking Union Medical College, Beilishi Road 167, Xicheng District, Beijing 100037, China. Email: wsymd@sina.com.

Background: The impact of septal myectomy on diastolic function in patients with obstructive hypertrophic cardiomyopathy is not well studied.

Methods: A transcatheter hemodynamic study was performed before and 3 to 6 months after septal myectomy in 12 patients with obstructive hypertrophic cardiomyopathy (HCM).

Results: Postoperative hemodynamic studies were done 4.4 \pm 1.2 months after myectomy. The left ventricular outflow tract peak-to-peak gradient decreased from $83.2 \pm 43.3 \mathrm{mmHg}$ preoperatively to $11.6 \pm 4.3 \mathrm{mmHg}$ after myectomy $(\mathrm{P}<0.00)$. The left ventricular diastolic time constant (Tau) was $64.2 \pm 26.1 \mathrm{~ms}$ before surgery and $42.2 \pm 15.7 \mathrm{~ms}$ postoperatively $(\mathrm{P}=0.029)$. The average left atrial pressure (LAP) decreased from 20.2 \pm 7.0 to $12.1 \pm 4.5 \mathrm{mmHg}$ after myectomy $(\mathrm{P}=0.008)$. Pulmonary artery hypertension was present in 6 patients preoperatively and remained in 2 patients after myectomy. Mean pulmonary artery pressure decreased from $29.3 \pm 16.2$ to $20 \pm 6.7 \mathrm{mmHg}$ after surgery $(\mathrm{P}=0.05)$, and the systolic pulmonary artery pressure decreased from $46 \pm 26.9$ to $30.5 \pm 8.3 \mathrm{mmHg}(\mathrm{P}=0.048)$. Pulmonary vascular resistance decreased from $5.7 \pm 4.1$ to $3.6 \pm 1.6$ wood after surgery $(\mathrm{P}=0.032)$.

Conclusions: Septal myectomy improved left ventricular diastolic function and subsequently relieved the right ventricular congestion in patients with obstructive HCM.

Keywords: Obstructive hypertrophic cardiomyopathy; myectomy surgery; diastolic function; cardiac catheterization; pulmonary hypertension

Submitted May 31, 2021. Accepted for publication Jul 23, 2021.

doi: $10.21037 /$ jtd-21-902

View this article at: https://dx.doi.org/10.21037/jtd-21-902

\section{Introduction}

Obstructive hypertrophic cardiomyopathy (HCM) is characterized by left ventricular outflow tract (LVOT) obstruction and diastolic dysfunction, which are the main causes of symptoms in many patients. In most symptomatic patients with obstructive HCM, appropriate management of the LVOT obstruction leads to a dramatic improvement of the symptoms. Septal myectomy is one of the most favorable options for the management of LVOT obstruction (1-3). The abnormal ejection hemodynamics are corrected immediately after myectomy. Septal myectomy showed excellent long-term outcomes in patients with obstructive 


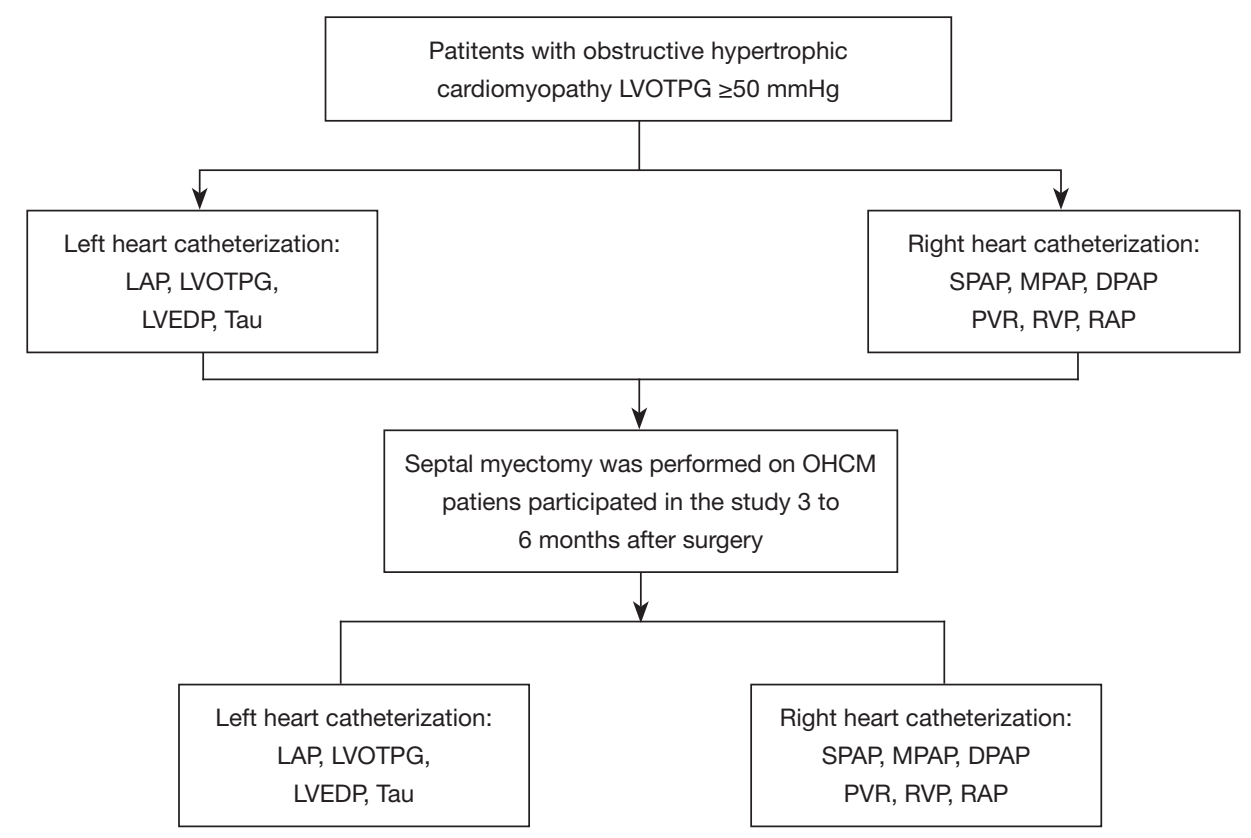

Figure 1 The flowchart of the study. LVOTPG, left ventricular outflow tract pressure gradient; LAP, left atrial pressure; LVEDP, left ventricular end diastolic pressure; SPAP, pulmonary artery systolic pressure; MPAP, mean pulmonary artery pressure; DPAP, pulmonary artery diastolic pressure; PVR, pulmonary vascular resistance; RVP, right ventricular pressure; RAP, right atrial pressure; OHCM, obstructive hypertrophic cardiomyopathy.

HCM whose symptoms were refractory to maximal medical treatment $(4,5)$.

The improvement of symptoms following septal myectomy may also be due to improvements of diastolic functions. Indirect data derived from imaging studies suggested decreased left atrial pressure (LAP) and pulmonary pressure after myectomy (6-12). However, the intrinsic relaxation of the left ventricle (LV) was not studied. Due to the complex diastolic hemodynamics in the presence of LVOT obstruction, estimates of the myocardial relaxation of the $\mathrm{LV}$ using a noninvasive approach were less reliable (13-15).

We present the following article in accordance with the STROBE reporting checklist (available at https://dx.doi. org/10.21037/jtd-21-902).

\section{Methods}

The study was conducted in accordance with the Declaration of Helsinki (as revised in 2013). The Institutional Review Board of Fuwai Hospital approved this study (NO. 2019-1206). All patients signed informed consents for the use of their data for research. Catheter examinations were performed approximately one week before the extended septal myectomy. Patients who voluntarily participated in a postoperative study came back to our institute for 3 to 6 months after surgery. Twelve patients completed preoperative and postoperative cardiac catheterization. Figure 1 shows the flowchart of this study.

\section{Study population}

Inclusion criteria: (I) age: 16-60 years old; (II) Class IIIII cardiac function [New York Heart Association (NYHA) classification]; and (III) left ventricular outflow tract pressure gradient (LVOTPG) $\geq 50 \mathrm{mmHg}$ at rest or on provocation.

Exclusion criteria: (I) the patient had a catheter examination within 1 month; (II) Contraindications for catheterization, such as stenosis or occlusion of peripheral arteries; (III) patients needed concomitant cardiovascular surgery at the time of septal myectomy or had prior cardiovascular surgeries; (IV) prior alcohol septal ablation; and $(\mathrm{V})$ patients with coronary heart disease.

\section{Cardiac catheterization}

A standard procedure was used following guidelines, 
including right heart catheterization (16) and left heart catheterization. A designated senior interventional physician performed cardiac catheterization in a catheterization room within 1 week before surgery and 3-6 months after surgery. The enrolled patients were examined in the supine position at rest. At the end of expiration, 3-5 cardiac beat pressure curves were obtained at each site. When obtaining the pressure curves, interferences, such as premature ventricular contraction and baseline instability, were excluded. The frequency of data collection was 240 times per second. All patients in this study underwent echocardiography before cardiac catheterization, and right cardiac catheterization followed by left cardiac catheterization during cardiac catheterization. The detailed catheterization method is described in the supplementary information. After obtaining a continuous pressure curve, 3-5 cardiac beats with stable left ventricular pressure curves were selected, we used monoexponential model to calculate the Tau value as previously reported by Weiss and associates $(17,18)$.

\section{Statistical analyses}

Continuous variables are presented as the means \pm standard deviation or the median (interquartile range). The normality of data was tested with the Kolmogorov-Smirnov test. Oneway analysis of variance was used to compare continuous variables between groups. The Kruskal-Wallis test was used for nonnormally distributed variables. Categorical data are expressed as the percentage frequency and were compared using the $\chi^{2}$ test or Fisher's exact test. Statistical analyses were performed using SPSS software (IBM SPSS Statistics for Macintosh, version 22.0; IBM Corp, Armonk, NY, USA). A P value $<0.05$ was considered statistically significant.

\section{Results}

\section{Clinical characteristics}

A total of 32 patients had preop study over the 8 months following the first enrollment. However, only 12 patients came back for postoperative test. Twelve patients met the inclusion criteria and agreed to be included in the study. Preoperatively, all patients exhibited medically refractory symptoms. Symptoms and NYHA class significantly improved after septal myectomy surgery. There was no significant difference in pre-myectomy and post-myectomy heart rate or hemoglobin level. No medication changes was made between the two cardiac catheterizations.

As previously described (9), a modified Morrow procedure was applied in this study. The weight of the myocardium removed was $12 \pm 6.7 \mathrm{~g}$. None of the study patient died during hospitalization or follow-up, and none required MV replacement. Non had postoperative constrictive pericarditis or other complication. The average time from surgery to postoperative echocardiography was $4.7 \pm 1.4$ months. Septum thickness decreased from $21.4 \pm 4.5 \mathrm{~mm}$ before surgery to $11.8 \pm 4.7 \mathrm{~mm}$ after surgery $(\mathrm{P}=0.03)$. The resting pressure gradient decreased from $69.5 \pm 23.7 \mathrm{mmHg}$ before surgery to $8.3 \pm 1.6 \mathrm{mmHg}$ after surgery $(\mathrm{P}<0.001)$. The baseline clinical characteristics and the clinical outcomes in the 12 study patients are summarized in Table 1.

\section{Preoperative and postoperative cardiac catheterization outcomes}

Postoperative cardiac catheterization was done $4.5 \pm 1.2$ months after myectomy. The left heart catheterization showed that the peak pressure gradient decreased from $83.2 \pm 43.3 \mathrm{mmHg}$ before surgery to $11.6 \pm 4.3 \mathrm{mmHg}$ after surgery $(\mathrm{P}<0.001)$. The right heart catheterization showed that mean pulmonary artery pressure (MPAP) decreased from $29.3 \pm 16.2 \mathrm{mmHg}$ preoperatively to $20 \pm 6.7 \mathrm{mmHg}$ $(\mathrm{P}=0.05)$ postoperatively, and the systolic pulmonary artery pressure decreased from $46 \pm 26.9$ to $30.5 \pm 8.3 \mathrm{mmHg}$ $(\mathrm{P}=0.048)$. Pulmonary vascular resistance $(\mathrm{PVR})$ decreased from 5.7 \pm 4.1 wood before surgery to $3.6 \pm 1.6$ wood after surgery $(\mathrm{P}=0.032)$. Tables 2 and 3 show the comparisons of heart catheterization.

\section{The outcomes of cardiac catheterization on ventricular diastolic function}

Common indicators of left ventricular diastolic function, such as left ventricular end diastolic pressure (LVEDP) measured in various parts of the $L V$ did not change significantly after surgery. Tau is defined as the time constant of isovolumic pressure decay in the early period of left ventricular relaxation, and it is calculated using the natural logarithm-time linear regression equation of left ventricular pressure $(17,18)$. This study also compared the pre- and postoperative changes in Tau of the right and LVs. The results showed that the preoperative Tau of the right ventricle was $62.4 \pm 75.6 \mathrm{~ms}$, and the postoperative Tau was $71.0 \pm 47.5 \mathrm{~ms}$. There was no significant difference $(\mathrm{P}=0.766)$. 
Table 1 Clinical characteristics before and 3-6 months after surgery

\begin{tabular}{|c|c|c|c|}
\hline Parameters & Preoperative & Postoperative & $P$ value \\
\hline Age (years) & $38.7 \pm 11.7$ & & \\
\hline Female gender & $4(33.3)$ & & \\
\hline Shortness of breath & $12(100.0)$ & $1(8.3)$ & \\
\hline Palpitation & $3(25.0)$ & $1(8.3)$ & \\
\hline Chest pain & $3(25.0)$ & 0 & \\
\hline Syncope & $2(16.7)$ & 0 & \\
\hline NYHA functional class & & & $<0.001$ \\
\hline NYHA I & 0 & $7(58.3)$ & \\
\hline NYHA II & $8(66.7)$ & $5(41.7)$ & \\
\hline NYHA III & $4(33.3)$ & 0 & \\
\hline NYHA IV & 0 & 0 & \\
\hline $\mathrm{HR}$ & $73.8 \pm 7.6$ & $70.7 \pm 11.7$ & 0.363 \\
\hline $\mathrm{AF}$ & $1(8.3)$ & $1(8.3)$ & - \\
\hline RBBB & $2(16.7)$ & $2(16.7)$ & - \\
\hline LBBB & $1(8.3)$ & $1(8.3)$ & - \\
\hline Pacemaker implantation & $1(8.3)$ & $1(8.3)$ & - \\
\hline \multicolumn{4}{|l|}{ Medications } \\
\hline Diuretic & $2(16.7)$ & $1(8.3)$ & - \\
\hline Beta-blocker & $12(100.0)$ & $12(100.0)$ & - \\
\hline Calcium channel blocker & 0 & 0 & - \\
\hline Pulmonary inodilators & 0 & 0 & \\
\hline $\mathrm{Hb}(\mathrm{g} / \mathrm{L})$ & $140.5 \pm 25.2$ & $141.4 \pm 21.9$ & 0.619 \\
\hline \multicolumn{4}{|l|}{ Echocardiography parameters } \\
\hline LAD (mm) & $44.5 \pm 10.8$ & $38.9 \pm 6.3$ & 0.049 \\
\hline LVEDD (mm) & $41.7 \pm 5.4$ & $45.6 \pm 5.7$ & 0.038 \\
\hline LVEF (\%) & $70.2 \pm 4.3$ & $63.7 \pm 4.3$ & 0.019 \\
\hline Interventricular septum thickness (mm) & $21.4 \pm 4.5$ & $11.8 \pm 4.7$ & 0.03 \\
\hline Maximal resting LVOT gradients $(\mathrm{mmHg})$ & $69.5 \pm 23.7$ & $8.3 \pm 1.6$ & $<0.001$ \\
\hline Resting MR & $1.5 \pm 0.8$ & $0.7 \pm 0.3$ & $<0.001$ \\
\hline 1 & 5 & 12 & \\
\hline 2 & 4 & 0 & \\
\hline 3 & 2 & 0 & \\
\hline 4 & 1 & 0 & \\
\hline $\mathrm{PH}$ & $1(8.3)$ & 0 & \\
\hline
\end{tabular}

Values are presented as the means $\pm \mathrm{SD}$, medians (IQR) or $\mathrm{n}(\%)$. The degree of MV regurgitation was a graded on a scale from 0 to 4 ( 0 = none, $1=$ mild; $2=$ moderate; $3=$ moderate to severe; and $4=$ severe). PH, pulmonary hypertension; IQR, interquartile range; NYHA, New York Heart Association; HR, heart rate; AF, atrial fibrillation; RBBB, complete right bundle branch block; LBBB, complete left bundle branch block; Hb, hemoglobin; LAD, left atrium diameter; LVEDD, left ventricular end-diastolic dimension; LVEF, left ventricular ejection fraction; LVOT, left ventricular outflow tract; MR, mitral valve regurgitation. 
Table 2 Comparison of right heart catheterization

\begin{tabular}{|c|c|c|c|}
\hline Parameters & Preoperative & Postoperative & $P$ value \\
\hline RAP-V peak (mmHg) & $8.1 \pm 3.7$ & $11.0 \pm 7.3$ & 0.239 \\
\hline MRAP (mmHg) & $6.7 \pm 3.4$ & $8.3 \pm 5.3$ & 0.384 \\
\hline MRVP (mmHg) & $19.7 \pm 12.4$ & $13.1 \pm 3.8$ & 0.139 \\
\hline DRVP (mmHg) & $6.9 .0 \pm 5.5$ & $5.1 \pm 3.3$ & 0.0335 \\
\hline MPAP (mmHg) & $29.3 \pm 16.2$ & $20.0 \pm 6.7$ & 0.05 \\
\hline SPAP (mmHg) & $46.0 \pm 26.9$ & $30.5 \pm 8.3$ & 0.048 \\
\hline DPAP (mmHg) & $19.7 \pm 10.2$ & $13.7 \pm 5.9$ & 0.062 \\
\hline MPAP $\geq 25 \mathrm{mmHg}$ & $6(50 \%)$ & $2(16.7 \%)$ & - \\
\hline MPAP $25-34 \mathrm{mmHg}$ & $4(33.3 \%)$ & $2(16.7 \%)$ & - \\
\hline MPAP $35-44 \mathrm{mmHg}$ & 0 & 0 & - \\
\hline MPAP $\geq 45 \mathrm{mmHg}$ & $2(16.7 \%)$ & 0 & - \\
\hline
\end{tabular}

Values are presented as the means \pm SD or $n(\%)$. IQR, interquartile range; RAP, right atrial pressure; MRAP, mean right atrial pressure; MRVP, mean right ventricular pressure; SRVP, right ventricular systolic pressure; DRVP, right ventricular diastolic pressure; MPAP, mean pulmonary artery pressure; SPAP, pulmonary artery systolic pressure; DPAP, pulmonary artery diastolic pressure; PVR, pulmonary vascular resistance.

The preoperative Tau of the LV Tau was $64.2 \pm 26.1 \mathrm{~ms}$, and the postoperative Tau was $42.2 \pm 15.7 \mathrm{~ms}$, which was significantly different $(\mathrm{P}=0.029)$. Figure 2 shows a typical change of LV change of pressure at follow-up. Figure 3 shows a change of time of left ventricular relaxation at follow-up. Table 3 presents the outcomes of cardiac catheterization on ventricular diastolic function.

Tau went down in 7 of the 12 patients and remained the same in the other 5 patients. The preop Tau was XX in the 7 decreased patients and $\mathrm{YY}$ in the 5 non-decreased patients. The 7 patients with higher preop Tau had their Tau reduced significantly postoperatively. The 7 patients with higher preoperative Tau have higher LOPTPG before surgery. Table 4 compares clinical parameters between Tau decreased patients and non-decreased patients.

\section{Discussion}

The present study investigated diastolic function using catheterization in patients with obstructive HCM before and after septal myectomy. The pressures of the left and right hearts were thoroughly investigated via direct measurement. The filling pressure and myocardial relaxation were significantly improved following myectomy, which are consistent with prior studies that showed a decrease in left atrial (LA) size (7-9), improvement of pulmonary artery hypertension (10-12), and reverse remodeling of the LV $(9,19)$. The results from the present study suggested that improvement of the diastolic function may be an important reason for the increased functional capacity following myectomy in patients with obstructive HCM, by improving cardiopulmonary function and NYHA.

LVOT obstruction is the main cause of symptoms in patients with HCM. For patients who are refractory to medical treatment, septal myectomy produces an excellent effect on the improvement of functional capacity and survival (1-5). An intraoperative hemodynamic study showed that the improvement of functional capacity may be due to the relief of obstruction and the increase in stroke volume (20). Many studies also showed that septal myectomy was associated with the improvement of diastolic function using an imaging approach (6-9). The method of evaluating 
Table 3 Outcomes of left heart catheterization and ventricular diastolic function

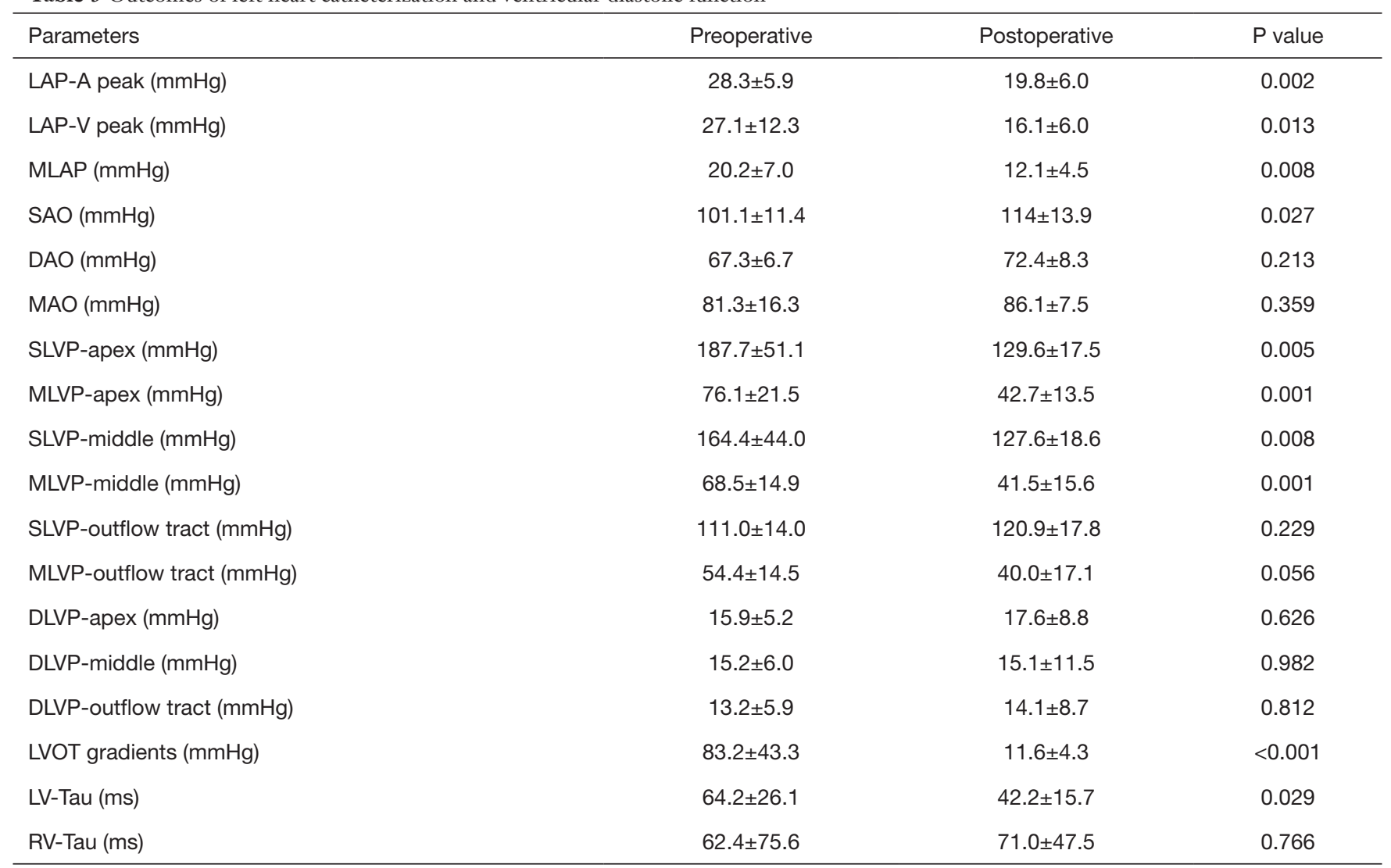

Values are presented as the means $\pm \mathrm{SD}$. IQR, interquartile range; LAP, left atrial pressure; MLAP, mean left atrial pressure; SAO, aortic systolic pressure; DAO, aortic diastolic pressure; MAO, mean aortic pressure; SLVP-apex, left ventricular apex systolic pressure; MLVPapex, mean left ventricular apex pressure; SLVP-middle, left ventricular middle segment systolic pressure; MLVP-middle, mean left ventricular middle segment pressure; SLVP-outflow tract, left ventricular outflow tract systolic pressure; MLVP-outflow tract, mean left ventricular outflow tract pressure; DLVP-apex, left ventricular apex diastolic pressure; DLVP-middle, left ventricular middle segment diastolic pressure; DLVP-outflow tract, left ventricular outflow tract diastolic pressure; LVOT, left ventricular outflow tract; LV, left ventricle; $\mathrm{RV}$, right ventricle; Tau, time constant of isovolumic pressure decay in early period of left ventricular relaxation.

diastolic function using imaging was derived from simpler hemodynamic circumstances and may not apply to the complex hemodynamics in patients with obstructive HCM (13-15). For example, Doppler echocardiographic estimates of left ventricular filling pressure using transmitral flows and mitral annular velocities modestly correlate with direct measurements of LAP (13).

Notably, the LA pressure and LV filling pressure decreased following septal myectomy, which were reported in many studies using different methods. Improvement of mitral valve regurgitation and increase in forwarding stroke volume significantly decrease the LA congestion. However, the improvement of myocardial relaxation was not well determined due to methodological limitations. Sorajja et al. found a variable effect of septal ablation on myocardial relaxation in patients with HCM (21). However, the postoperative measurements were performed during the ablation procedure and may have been affected by the acute myocardial necrosis. Postoperative measurements in the present study were performed three to six months after myectomy, when the hemodynamics and myocardium had recovered from the acute surgical phase. The data showed a decrease in the Tau value after myectomy, which indicates an improvement in $\mathrm{LV}$ relaxation. Several changes after myectomy may induce the improvement. Myocardial ischemia has a vital impact on the Tau value, and it is present in many patients with HCM (22). The relief of LVOT obstruction considerably decreases the oxygen consumption of the myocardium. These factors together contribute to the improvement of myocardial ischemia and stiffness. 

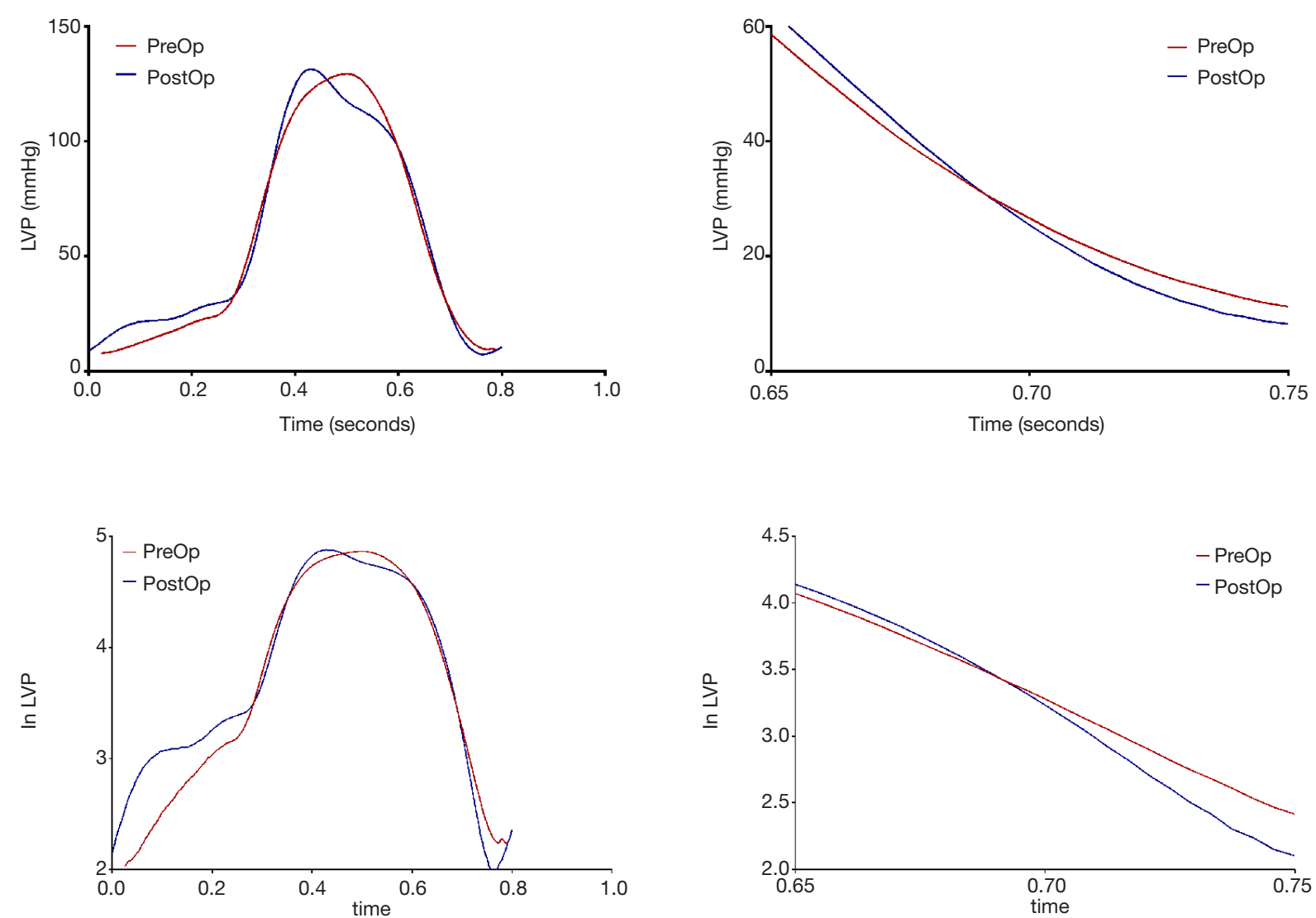

Figure $2 \mathrm{LV}$ pressure tracings before and after septal myectomy. The height of the pressure curve has been adjusted. The upper left panel shows the LV pressure in a heartbeat before septal myectomy and a heartbeat at a 3-month follow up, and the upper right panel shows the part of the pressure tracings in LV relaxation. The pressure tracings show the LV pressure decreases faster at follow-up. The lower left panel shows the converted LV pressure by natural logarithm, and the lower right panel shows the LV relaxation part of ln (LV pressure). The steeper slope of follow-up $\ln (\mathrm{LV}$ pressure) in $\mathrm{LV}$ relaxation demonstrates the decrease of tau value. $\mathrm{LV}$, left ventricle.

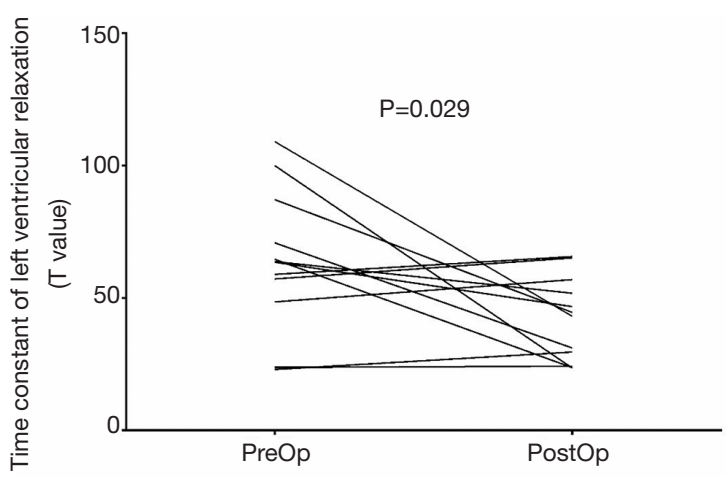

Figure 3 Change of tau value at a 3 -month follow-up. The tau value decreased overall at follow-up and the decrease is especially significant in those who have a large tau value before myectomy.
Thinning of the ventricular septum may be another reason for the improvement of myocardial relaxation. The $\mathrm{LV}$ in patients with obstructive HCM is generally characterized by asymmetric hypertrophy, which predominantly presents as septal hypertrophy, especially basal septal hypertrophy. This hypertrophy is an important cause of the LV systolic and diastolic dysfunction. Septal myectomy may improve global LV compliance by thinning the thickest part of the $\mathrm{LV}$, which was demonstrated by the echocardiographic data in the present study and prior studies $(9,19,23)$. There was a regression in the left ventricular hypertrophy following myectomy. A prior study also showed a continuous decrease of $\mathrm{N}$-terminal pro-brain natriuretic peptide months after myectomy (24). Therefore, the reverse remodeling of the 
Table 4 Comparisons of clinical parameters between Tau decreased patients and non-decreased patients

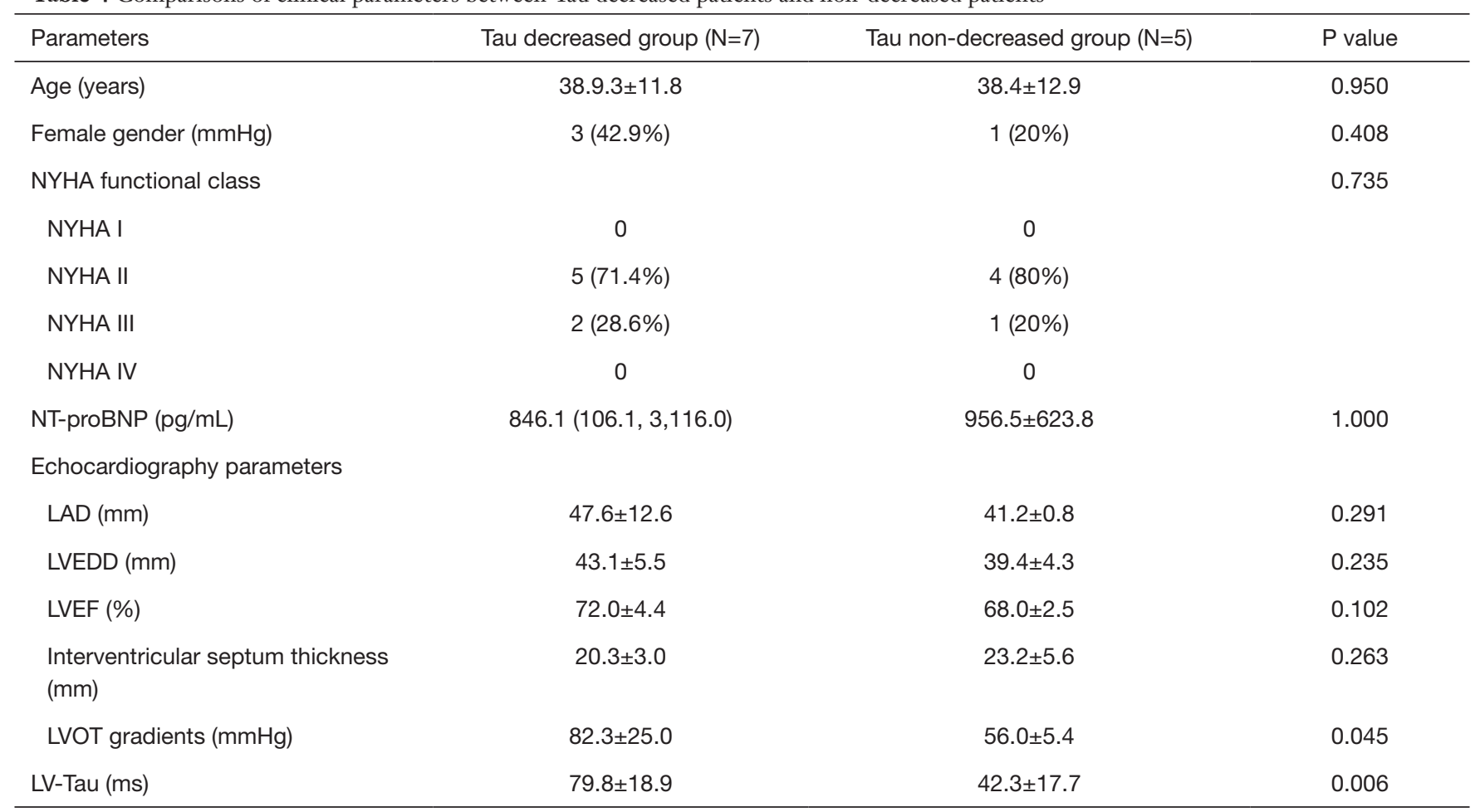

Values are presented as the means $\pm \mathrm{SD}$, medians (IQR) or $n$ (\%). IQR, interquartile range; NYHA, New York Heart Association; LAD, left atrium diameter; LVEDD, left ventricular end-diastolic dimension; LVEF, left ventricular ejection fraction; LVOT, left ventricular outflow tract; LV, left ventricle.

LV may also contribute to the improvement of diastolic function.

Our results showed that the 7 patients with higher preoperative Tau had their Tau reduced significantly postop. And the 7 patients with decreased Tau seems to have higher LOPTPG before surgery. In 5 patients, Tau did not change significantly due to a relatively lower baseline value. We speculate patients with worse diastolic function and higher LOPTPG may benefit more from myectomy surgery, and the Tau decreased more significantly postoperatively. We conclude that septal myectomy decreased the Tau, especially in those who had an increased baseline Tau. Though we need to prove our speculation by increasing the sample volume.

There was also a significant improvement in pulmonary artery hypertension. Pulmonary circular volume increased, and pulmonary artery pressure decreased. Notably, pulmonary vascular resistance also decreased. This result is consistent with prior studies on post-myectomy changes of pulmonary artery pressure using imaging methods $(10-12,25)$. The mechanism may be improvement of the vascular congestion. However, the right ventricular and right atrial pressure were not apparently affected.

\section{Limitations}

There were several limitations in the present study. The study size was relatively small, which limited the power of the conclusions. Patients voluntarily decided whether to undergo the postoperative study, so the comparison was done in only 12 patients. There may be a selection bias in sampling.

\section{Conclusions}

Patients with obstructive HCM have improved diastolic function following septal myectomy, especially in those who had an increased baseline Tau. The improvement was indicated by decreased LA and LV filling pressures and improved LV relaxation. Cardiac output and pulmonary vascular congestion were also improved.

\section{Acknowledgments}

Funding: This study was supported by Clinical and Translational Research Fund of Chinese Academy of 
Medical Sciences, Grant/Award Number: 2019XK320054 and Capital's Funds for Health Major Project of the Beijing Municipal Commission of Health, Grant/Award Number: 2020-2-4036.

\section{Footnote}

Reporting Checklist: The authors have completed the STROBE reporting checklist. Available at https://dx.doi. org/10.21037/jtd-21-902

Data Sharing Statement: Available at https://dx.doi. org/10.21037/jtd-21-902

Peer Review File: Available at https://dx.doi.org/10.21037/ jtd-21-902

Conflicts of Interest: All authors have completed the ICMJE uniform disclosure form (available at https://dx.doi. org/10.21037/jtd-21-902). The authors have no conflicts of interest to declare.

Ethical Statement: The authors are accountable for all aspects of the work in ensuring that questions related to the accuracy or integrity of any part of the work are appropriately investigated and resolved. The study was conducted in accordance with the Declaration of Helsinki (as revised in 2013). The study was approved by The Institutional Review Board of Fuwai Hospital (NO.20191206) and informed consent was taken from all the patients.

Open Access Statement: This is an Open Access article distributed in accordance with the Creative Commons Attribution-NonCommercial-NoDerivs 4.0 International License (CC BY-NC-ND 4.0), which permits the noncommercial replication and distribution of the article with the strict proviso that no changes or edits are made and the original work is properly cited (including links to both the formal publication through the relevant DOI and the license). See: https://creativecommons.org/licenses/by-nc-nd/4.0/.

\section{References}

1. Ommen SR, Maron BJ, Olivotto I, et al. Long-term effects of surgical septal myectomy on survival in patients with obstructive hypertrophic cardiomyopathy. J Am Coll Cardiol 2005;46:470-6.

2. Smedira NG, Lytle BW, Lever HM, et al. Current effectiveness and risks of isolated septal myectomy for hypertrophic obstructive cardiomyopathy. Ann Thorac Surg 2008;85:127-33.

3. Woo A, Williams WG, Choi R, et al. Clinical and echocardiographic determinants of long-term survival after surgical myectomy in obstructive hypertrophic cardiomyopathy. Circulation 2005;111:2033-41.

4. Authors/Task Force members; Elliott PM, Anastasakis A, et al. 2014 ESC Guidelines on diagnosis and management of hypertrophic cardiomyopathy: the Task Force for the Diagnosis and Management of Hypertrophic Cardiomyopathy of the European Society of Cardiology (ESC). Eur Heart J 2014;35:2733-79.

5. Maron BJ, Rowin EJ, Casey SA, et al. How Hypertrophic Cardiomyopathy Became a Contemporary Treatable Genetic Disease With Low Mortality: Shaped by 50 Years of Clinical Research and Practice. JAMA Cardiol 2016;1:98-105.

6. Tower-Rader A, Furiasse N, Puthumana JJ, et al. Effects of septal myectomy on left ventricular diastolic function and left atrial volume in patients with hypertrophic cardiomyopathy. Am J Cardiol 2014;114:1568-72.

7. Finocchiaro G, Haddad F, Kobayashi Y, et al. Impact of Septal Reduction on Left Atrial Size and Diastole in Hypertrophic Cardiomyopathy. Echocardiography 2016;33:686-94.

8. Williams LK, Chan RH, Carasso S, et al. Effect of Left Ventricular Outflow Tract Obstruction on Left Atrial Mechanics in Hypertrophic Cardiomyopathy. Biomed Res Int 2015;2015:481245.

9. Tang B, Song Y, Yang Q, et al. Changes in left atrial function, left ventricle remodeling, and fibrosis after septal myectomy for obstructive hypertrophic cardiomyopathy. J Thorac Cardiovasc Surg 2020. [Epub ahead of print]. doi: 10.1016/j.jtcvs.2020.06.017.

10. Musumeci MB, Mastromarino V, Casenghi M, et al. Pulmonary hypertension and clinical correlates in hypertrophic cardiomyopathy. Int J Cardiol 2017;248:326-32.

11. Geske JB, Konecny T, Ommen SR, et al. Surgical myectomy improves pulmonary hypertension in obstructive hypertrophic cardiomyopathy. Eur Heart J 2014;35:2032-9.

12. Covella M, Rowin EJ, Hill NS, et al. Mechanism of Progressive Heart Failure and Significance of Pulmonary Hypertension in Obstructive Hypertrophic Cardiomyopathy. Circ Heart Fail 2017;10:e003689.

13. Geske JB, Sorajja P, Nishimura RA, et al. Evaluation of left ventricular filling pressures by Doppler echocardiography in patients with hypertrophic cardiomyopathy: correlation 
with direct left atrial pressure measurement at cardiac catheterization. Circulation 2007;116:2702-8.

14. Rakowski H, Carasso S. Quantifying diastolic function in hypertrophic cardiomyopathy: the ongoing search for the holy grail. Circulation 2007;116:2662-5.

15. Lu DY, Haileselassie B, Ventoulis I, et al. E/e' ratio and outcome prediction in hypertrophic cardiomyopathy: the influence of outflow tract obstruction. Eur Heart J Cardiovasc Imaging 2018;19:101-7. Erratum in: Eur Heart J Cardiovasc Imaging 2018;19:121.

16. Galiè N, Humbert M, Vachiery JL, et al. 2015 ESC/ERS Guidelines for the diagnosis and treatment of pulmonary hypertension: The Joint Task Force for the Diagnosis and Treatment of Pulmonary Hypertension of the European Society of Cardiology (ESC) and the European Respiratory Society (ERS): Endorsed by: Association for European Paediatric and Congenital Cardiology (AEPC), International Society for Heart and Lung Transplantation (ISHLT). Eur Heart J 2016;37:67-119.

17. Weiss JL, Frederiksen JW, Weisfeldt ML. Hemodynamic determinants of the time-course of fall in canine left ventricular pressure. J Clin Invest 1976;58:751-60.

18. Mirsky I. Assessment of diastolic function: suggested methods and future considerations. Circulation 1984;69:836-41.

19. El-Hamamsy I, Lekadir K, Olivotto I, et al. Pattern

Cite this article as: Yang Q, Cui H, Zhu C, Hu H, Lv J, Liu Y, Zhang Y, Schaff HV, Wang S. Impact of septal myectomy on diastolic function in patients with obstructive hypertrophic cardiomyopathy. J Thorac Dis 2021;13(8):4925-4934. doi: $10.21037 /$ jtd-21-902 and degree of left ventricular remodeling following a tailored surgical approach for hypertrophic obstructive cardiomyopathy. Glob Cardiol Sci Pract 2012;2012:9.

20. Cui H, Schaff HV, Abel MD, et al. Left ventricular ejection hemodynamics before and after relief of outflow tract obstruction in patients with hypertrophic obstructive cardiomyopathy and valvular aortic stenosis. J Thorac Cardiovasc Surg 2020;159:844-852.e1.

21. Sorajja P, Nishimura RA, Ommen SR, et al. Effect of septal ablation on myocardial relaxation and left atrial pressure in hypertrophic cardiomyopathy an invasive hemodynamic study. JACC Cardiovasc Interv 2008;1:552-60.

22. Ohsato K, Shimizu M, Sugihara N, et al. Histopathological factors related to diastolic function in myocardial hypertrophy. Jpn Circ J 1992;56:325-33.

23. Deb SJ, Schaff HV, Dearani JA, et al. Septal myectomy results in regression of left ventricular hypertrophy in patients with hypertrophic obstructive cardiomyopathy. Ann Thorac Surg 2004; 78:2118-22.

24. Cui H, Wu X, Wang S, et al. Time and age dependent decrease of NT-proBNP after septal myectomy in hypertrophic obstructive cardiomyopathy. Clin Chem Lab Med 2017;55:1614-20.

25. Mitra A, Ghosh RK, Bandyopadhyay D, et al. Significance of Pulmonary Hypertension in Hypertrophic Cardiomyopathy. Curr Probl Cardiol 2020;45:100398. 